\title{
De novo acute hepatitis $B$ in myeloperoxidase-specific anti-neutrophil cytoplasmic autoantibody-related microscopic polyangiitis treated with corticosteroids
}

\author{
Yoichi Iwafuchi · Yuko Oyama · Takashi Morita • \\ Akira Kamimura $\cdot$ Shigeru Miyazaki $\cdot$ \\ Ichiei Narita
}

Received: 1 May 2012/Accepted: 9 August 2012/Published online: 12 September 2012

(C) Japanese Society of Nephrology 2012

\begin{abstract}
An 82-year-old female was referred to our hospital because of low-grade fever, anemia, and rapidly progressive nephritic syndrome. Her laboratory data showed mild proteinuria, mild renal failure, and the presence of myeloperoxidase-specific anti-neutrophil cytoplasmic autoantibody. A skin biopsy specimen taken from the erythematous purpura revealed neutrophilic infiltration around the blood vessels with fibrinoid changes in the vessel walls. A renal biopsy specimen revealed segmental necrotizing glomerulonephritis with fibro-cellular crescent formation without deposits of immunoglobulin or complement components, indicating microscopic polyangiitis. The use of corticosteroid treatment, including intravenous methylprednisolone, improved renal failure. After 4 years with low-dose maintenance corticosteroid therapy, she developed de novo acute hepatitis B, and entecavir was remarkably effective, showing a rapid recovery from liver dysfunction with jaundice. To prevent hepatitis B virus
\end{abstract}

Y. Iwafuchi $(\bowtie) \cdot$ Y. Oyama · A. Kamimura

Department of Internal Medicine, Koseiren Sanjo General

Hospital, 5-1-62 Tsukanome, Sanjo 955-0055, Japan

e-mail: iwafuchiy@hotmail.com

T. Morita

Department of Pathology, Shinrakuen Hospital, 3-3-11

Shindoriminami, Nishi-ku, Niigata 950-2087, Japan

S. Miyazaki

Department of Internal Medicine, Kidney Center, Shinrakuen

Hospital, 3-3-11 Shindoriminami,

Nishi-ku, Niigata 950-2087, Japan

I. Narita

Clinical Nephrology and Rheumatology, Department

of Medicine II, Niigata University Graduate School of Medical

and Dental Sciences, 1-754 Asahimachi-Dori, Chuo-ku,

Niigata 951-8510, Japan
(HBV) reactivation and de novo acute hepatitis B induced by immunosuppressive or cytotoxic therapy, including corticosteroids alone, the measurement of HBV-related serological markers needs to be performed prior to the initiation of such therapy, even in renal diseases.

Keywords Hepatitis B virus reactivation .

De novo acute hepatitis B - Microscopic polyangiitis .

Corticosteroids - Immunosuppressive or cytotoxic therapy · Entecavir

\section{Introduction}

Hepatitis B is the most common serious liver infection in the world. Approximately one-third of the world's population has been infected at one point in their lives, including 350 million people who are chronic carriers. The majority of carriers who develop hepatitis $\mathrm{B}$ e antigen ( $\mathrm{HBeAg})$ seroconversion remain $\mathrm{HBeAg}$-negative and hepatitis B e antibody (HBeAb)-positive, with normal alanine aminotransferase (ALT) levels and minimal or no necroinflammation on liver biopsy. This has been referred to as the "inactive carrier state" [1]. Hepatitis B virus (HBV) reactivation is a well-known phenomenon in chronic HBV carriers and it represents a life-threatening complication following cytotoxic or other immunosuppressive anticancer therapy. Furthermore, in hepatitis B surface antigen (HBsAg)-negative patients, the presence of hepatitis B core antibody ( $\mathrm{HBcAb}$ ), irrespective of the detection of hepatitis B surface antibody (HBsAb), is correlated with a significant risk of de novo hepatitis B infection following cytotoxic or immunosuppressive therapy [2]; however, following simple corticosteroid therapy, these pathophysiological phenomena will infrequently 
occur. We report a female with myeloperoxidase-specific anti-neutrophil cytoplasmic autoantibody (MPO-ANCA)related microscopic polyangiitis (MPA) who developed de novo acute hepatitis B (DNH) following simple corticosteroid therapy.

\section{Case report}

An 82-year-old female was referred to our hospital because of low-grade fever, anemia, and rapidly progressive nephritic syndrome. She had hypertension, which was treated with amlodipine and losartan for 5 years, but had been in good health until 12 weeks before admission, when she noted low-grade fever and anorexia. She was admitted to a nearby hospital because of low-grade fever and arthralgia of 3 weeks duration. Her serum creatinine (Cre) level was $0.75 \mathrm{mg} / \mathrm{dl}$ and estimated glomerular filtration rate (eGFR) was $55.4 \mathrm{ml} / \mathrm{min} / 1.73 \mathrm{~m}^{2}$ at first. She was treated with antibiotics, but her fever persisted, and her Cre level gradually became elevated to $1.47 \mathrm{mg} / \mathrm{dl}$ (eGFR $26.6 \mathrm{ml} / \mathrm{min} / 1.73 \mathrm{~m}^{2}$ ). Rapidly progressive nephritic syndrome was suspected and she was found to be positive for MPO-ANCA. Therefore, she was transferred to our hospital for treatment.

On examination, the patient's blood pressure was $136 / 80 \mathrm{mmHg}$, pulse was 92 beats/min, and temperature was $37.3{ }^{\circ} \mathrm{C}$. She was slightly anemic and not icteric. The heart and lungs were normal, the liver and spleen were not palpable, and lymph nodes were not palpable. An erythematous purpura was observed and mild peripheral edema was present.

Urinary protein was $0.3-0.7 \mathrm{~g} / 24 \mathrm{~h}$ and the urinary sediment showed 1-4 erythrocytes and 1-4 leukocytes per high-power field. Her hematocrit level was $23.0 \%$, hemoglobin concentration was $7.5 \mathrm{~g} / \mathrm{dl}$, platelet count was $489,000 / \mu \mathrm{l}$, and leukocyte count was $19,370 / \mu 1$. The serum urea nitrogen (UN) level was $45.5 \mathrm{mg} / \mathrm{dl}$, the Cre level was $2.35 \mathrm{mg} / \mathrm{dl}$, the eGFR was $15.9 \mathrm{ml} / \mathrm{min} / 1.73 \mathrm{~m}^{2}$, the uric acid (UA) level was $8.8 \mathrm{mg} / \mathrm{dl}$, the cholesterol level was $117 \mathrm{mg} / \mathrm{dl}$, the total protein level was $7.2 \mathrm{~g} / \mathrm{dl}$, the albumin level was $2.2 \mathrm{~g} / \mathrm{dl}$, the total bilirubin level was $0.23 \mathrm{mg} / \mathrm{dl}$, the aspartate aminotransferase (AST) level was $42 \mathrm{IU} / \mathrm{l}$, the ALT level was $29 \mathrm{IU} / \mathrm{l}$, the lactate dehydrogenase (LDH) level was $158 \mathrm{IU} / \mathrm{l}$, the alkaline phosphatase (ALP) level was $399 \mathrm{IU} / \mathrm{l}$, and the gamma glutamyl transpeptidase (GGT) level was $22 \mathrm{IU} / \mathrm{l}$. The C-reactive protein (CRP) level was $10.22 \mathrm{mg} / \mathrm{dl}$, IgG was $1261 \mathrm{mg} / \mathrm{dl}, \operatorname{IgA}$ was $255 \mathrm{mg} / \mathrm{dl}$, IgM was $87 \mathrm{mg} / \mathrm{dl}$, and ferritin was $333 \mathrm{ng} / \mathrm{ml}$. Serum C3, C4, and total serum hemolytic activity were normal. Circulating immune complexes were negative. MPO-ANCA was positive with a titer of $80 \mathrm{EU}$, but antiproteinase3-specific ANCA was negative. Anti-glomerular basement membrane antibody was negative. Rheumatoid factor, antistreptolysin-O, HBsAg, hepatitis C virus (HCV) antibody, human immunodeficiency virus antibody, antinuclear antibody, and cryoglobulin were all negative. A chest X-ray showed mild cardiomegaly and an electrocardiogram showed ST segment depressions of $V_{2}$ and $V_{3}$. Renal echogram and computed tomography showed kidneys which were normal in size.

Therefore, we promptly initiated a 3-day course of intravenous methylprednisolone $(500 \mathrm{mg} /$ day $)$ followed by oral prednisolone (PSL) at $20 \mathrm{mg} /$ day. After this therapy, the patient's symptoms, including low-grade fever, anorexia, and skin lesions, rapidly diminished, along with a decrease in CRP levels to within the normal range. A skin biopsy specimen taken from the erythematous purpura revealed neutrophilic infiltration around the blood vessels, with fibrinoid changes in the vessel walls. On the 20th hospital day, a renal biopsy was performed to investigate the cause of rapidly progressive nephritic syndrome. Under light microscopy, 28 glomeruli were found, eight were obsoleted and seven were obsoleting with collapsed tufts. Four glomeruli showed segmental sclerosing changes with small fibro-cellular crescent, and one glomerulus had segmental necrotizing changes involving vas afferens with small cellular crescents (Fig. 1). The remaining glomeruli, except for a few showing mild ischemic changes, appeared almost normal. There were several focal areas of severe interstitial changes with cellular infiltration and tubular damages. Obsoleted and obsoleting glomeruli were located mainly in these areas, and glomeruli with mild changes in the areas also had mildly collapsing tufts (Fig. 2). Active vasculitis with fibrinoid change was not found, but there was a distorted artery with disruption of the internal elastic lamina. These findings were interpreted as compatible with those of segmental necrotizing glomerulonephritis of 15 weeks old but still active. By immunofluorescence study, no significant deposits of immunoglobulins or complement components were found. Based on the skin and renal histological findings and laboratory findings, the patient was diagnosed as having MPA. Eight weeks after admission, oral PSL was tapered off to $15 \mathrm{mg}$ daily and, after 1 week, she was discharged. At that time, her Cre level was $1.26 \mathrm{mg} / \mathrm{dl}$ (eGFR, $31.4 \mathrm{ml} / \mathrm{min} / 1.73 \mathrm{~m}^{2}$ ), and then she was treated in our outpatient clinic once a month. Almost every 4 weeks, a routine blood and urine test was performed to investigate the presence of exacerbation of renal function. Approximately 4 years after admission, PSL was slowly tapered off to $5 \mathrm{mg}$ daily (Fig. 3).

Six weeks before the second admission, PSL was tapered off to $3 \mathrm{mg}$ from $5 \mathrm{mg}$ daily. Approximately 4 weeks later, the patient developed anorexia and was easily fatigued. Shortly thereafter, she developed jaundice on her conjunctivae and skin. Therefore, she was admitted 


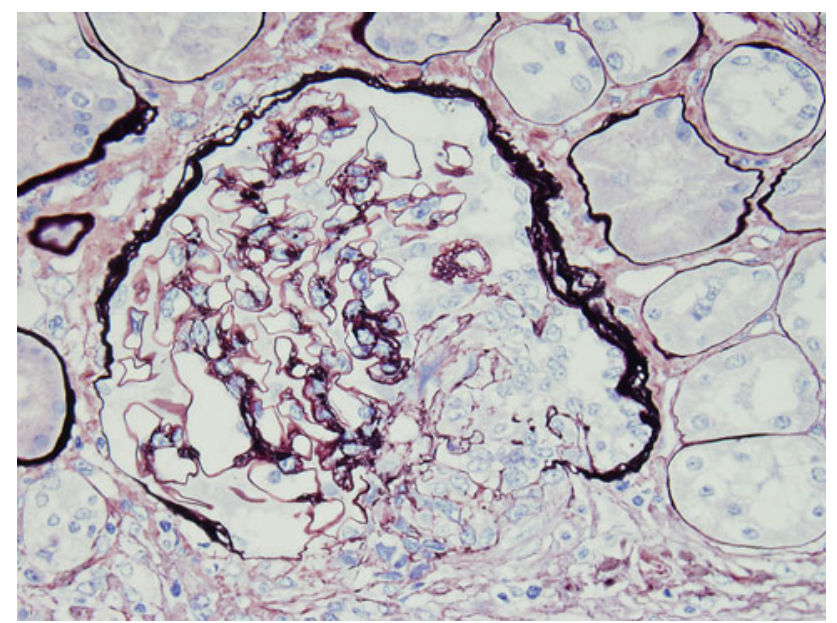

Fig. 1 One glomerulus showing segmental necrotizing changes involving the vas afferens and small cellular crescents (periodic acid methenamine silver)

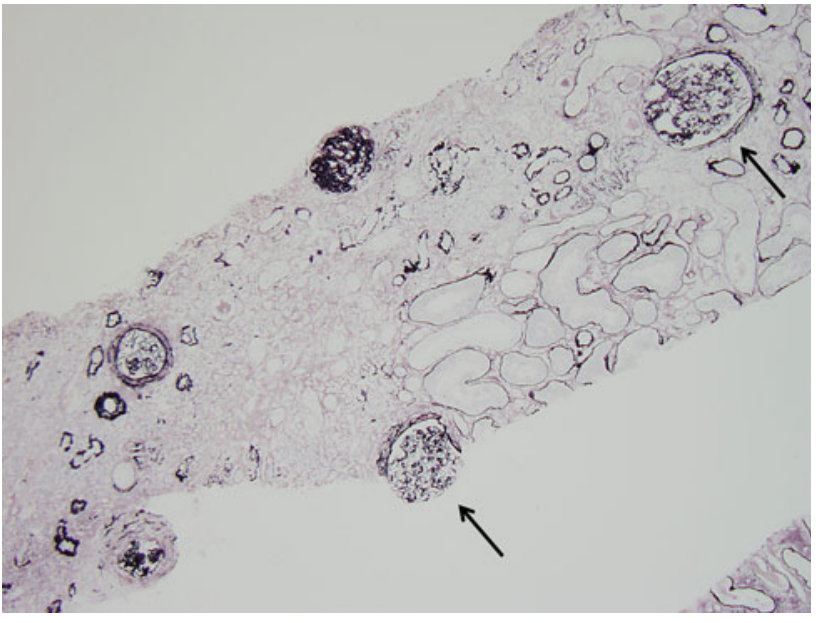

Fig. 2 An area of severe interstitial changes with cellular infiltration and tubular damages, where obsoleted and obsoleting glomeruli are located and two glomeruli (arrows) have mildly collapsing tufts and lamellated Bowman's capsule (periodic acid methenamine silver)

to our hospital again for further evaluation and treatment. Physical examination showed mild jaundice and bilateral pretibial edema. The liver and spleen were not palpable. Her laboratory data showed acute exacerbation of chronic renal failure and severe liver biochemistry as follows: $\mathrm{UN}$, $139.5 \mathrm{mg} / \mathrm{dl}$; Cre, $9.74 \mathrm{mg} / \mathrm{dl}$; eGFR, $3.3 \mathrm{ml} / \mathrm{min} / 1.73 \mathrm{~m}^{2}$; UA, $10.5 \mathrm{mg} / \mathrm{dl}$; total bilirubin, $5.65 \mathrm{mg} / \mathrm{dl}$; direct bilirubin, $3.93 \mathrm{mg} / \mathrm{dl}$; AST, $630 \mathrm{IU} / \mathrm{l}$; ALT, $655 \mathrm{IU} / \mathrm{l}$; LDH, $506 \mathrm{IU} / \mathrm{l}$; ALP, $368 \mathrm{IU} / \mathrm{l}$; and GGT, $320 \mathrm{IU} / \mathrm{l}$. Using the frozen serum, which was taken at the first admission, we re-checked the HBsAg, HBV DNA, and anti-HCV results, which were all negative, but the $\mathrm{HBs} \mathrm{Ab}$ and $\mathrm{HBcAb}$ results were positive. Furthermore, HBsAg was positive in her serum at the second admission, whereas anti-HBc IgM was negative, indicating that this acute hepatitis $\mathrm{B}$ was caused by $\mathrm{HBV}$ reactivation. The titer of HBV DNA was high at $7.6 \mathrm{log}$ copies $/ \mathrm{ml}$. Based on the diagnosis of $\mathrm{DNH}$, which was caused by the reactivation of $\mathrm{HBV}$, an oral weekly dose $(0.5 \mathrm{mg})$ of entecavir was immediately started on the second hospital day. Following entecavir administration, the serum HBV DNA level gradually fell and became undetectable at 4 weeks, and transaminase and bilirubin levels gradually fell to within the normal range at 5 weeks (Fig. 3) The patient's renal function temporarily deteriorated. Consequently, she received hemodialysis treatment three times a week during the following 2 weeks. We concluded that MPA did not recur because MPO-ANCA levels remained undetectable on this admission. Therefore, we considered that the main causes of her acute exacerbation of chronic renal failure were dehydration and hepato-renal syndrome as a result of DNH. The patient was discharged on the 52nd hospital day. At that time, the level of HBV DNA in her serum remained under the lower limit of detection, and transaminase and bilirubin levels were normal. Her renal function returned to its previous level (Cre, $2.05 \mathrm{mg} / \mathrm{dl}$; eGFR, $18.2 \mathrm{ml} / \mathrm{min} / 1.73 \mathrm{~m}^{2}$ ). She was then treated in our outpatient clinic once a month again, and entecavir administration was continued. After the administration of entecavir, the level of HBV DNA in the serum remained negative. However, her renal function slowly deteriorated. Approximately 16 months after her second admission, her Cre level reached $4.56 \mathrm{mg} / \mathrm{dl}$ (eGFR, $7.6 \mathrm{ml} / \mathrm{min} / 1.73 \mathrm{~m}^{2}$ ) and her heart failure worsened and, therefore, she began receiving maintenance hemodialysis. She continued maintenance hemodialysis for approximately 2 years until death due to congestive heart failure, and liver dysfunction was not observed by this time.

\section{Discussion}

Reactivation of HBV is becoming a well-recognized complication in patients with chronic HBV infection who are undergoing immunosuppressive or cytotoxic therapy [2]. The reactivation of HBV replication with an increase in serum HBV DNA and ALT levels has been reported in $20-50 \%$ of hepatitis B carriers undergoing immunosuppressive or cancer chemotherapy [1]. The risk of HBV reactivation is much lower in patients with resolved infection, but the reactivation of $\mathrm{HBV}$ has been reported not only in HBsAg-positive patients undergoing immunosuppressive or cytotoxic therapy, but also in a proportion of HBsAg-negative patients with $\mathrm{HBc}$ antibody and/or HBs antibody. Currently, there is insufficient information to recommend routine prophylaxis for these individuals $[1,3]$. Furthermore, DNH is defined as hepatitis B occurring in a patient who has an HBsAb- and/or HBcAb-positive status 
Fig. 3 The clinical course of the patient. Entecavir was remarkably effective, and the patient showed a rapid recovery from liver dysfunction with jaundice. $P S L$ prednisolone, M-PSL Pulse intravenous methylprednisolone pulse therapy, T.Bil total bilirubin, $A S T$ aspartate aminotransferase, GGT gamma glutamyl transpeptidase, $H D$ hemodialysis

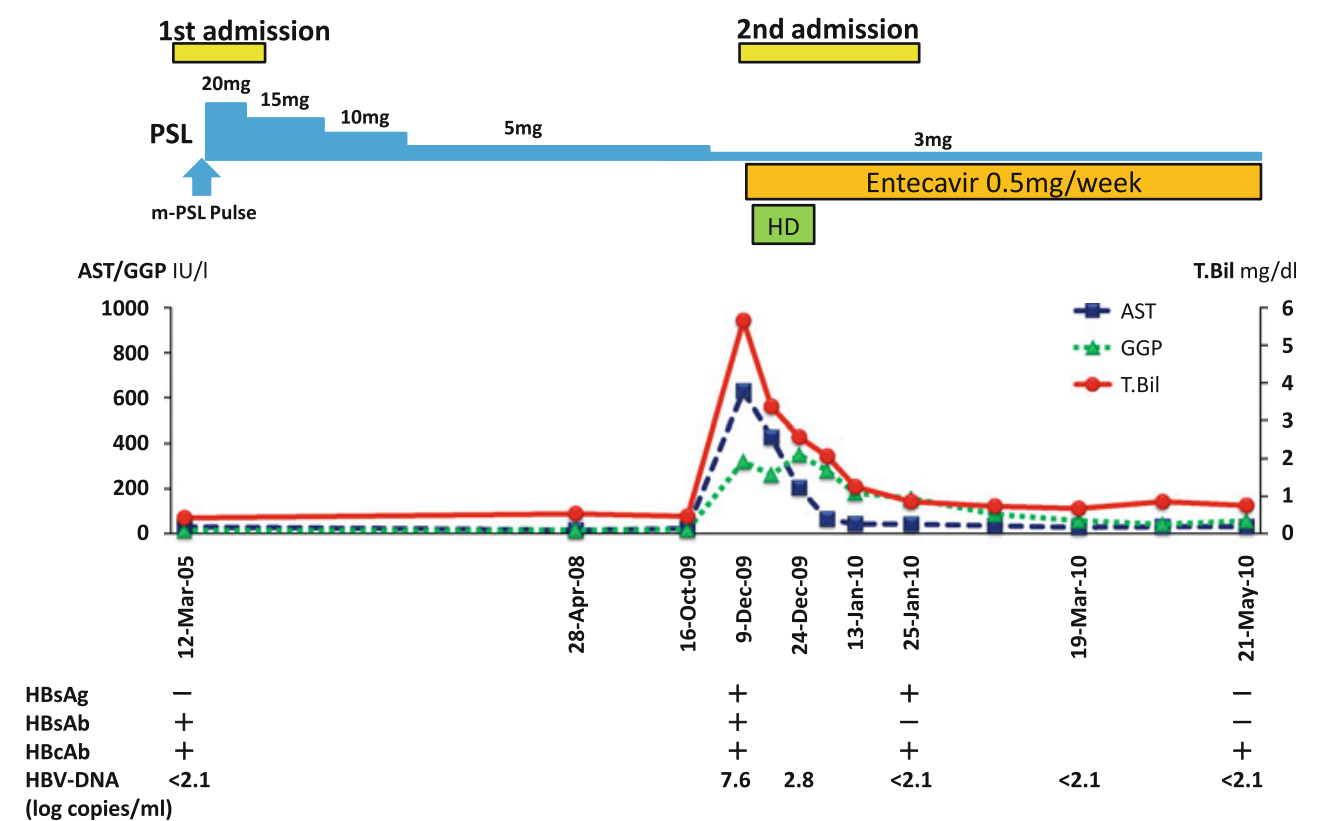

by HBV reactivation; DNH can be induced by immunosuppressive or cytotoxic therapy. Cases of fatal DNH following immunosuppressive or cytotoxic therapy for some diseases have been reported [4].

Microscopic polyangiitis is a type of vasculitis that affects small blood vessels, such as capillaries, venules, or arterioles. ANCA-positive MPA should be considered as part of the spectrum of ANCA-associated small-vessel vasculitis, ranging from renal-limited rapidly progressive glomerulonephritis (RPGN) to multisystem diseases, including Wegener's granulomatosis and Churg-Strauss syndrome $[5,6]$. Corticosteroids are frequently used in the treatment of ANCA-positive RPGN. In 2002, Sakai et al. [7] published a Japanese version of the RPGN clinical guidelines based on data for 715 RPGN patents collected until 2001. Yamagata, who was a coauthor of the guidelines (2nd edition) in 2011, and colleagues reported that an oral PSL dose $<0.8 \mathrm{mg} / \mathrm{kg} /$ day with or without cyclophosphamide as an initial treatment could improve patient survival in older Japanese ANCA-associated vasculitis/ RPGN patients [8]. Our case was elderly, so she was treated with intravenous methylprednisolone and oral PSL without cyclophosphamide. In our case, positivity of HBsAg and HBV-DNA was demonstrated after 6 weeks when corticosteroids were reduced to $3 \mathrm{mg}$ from $5 \mathrm{mg}$. At this time, she did not have any other immunosuppressive or cytotoxic drugs, and she was diagnosed with DHN. Corticosteroids are widely used as a treatment for chronic kidney diseases, allergies, collagen disease, and autoimmune disorders, among others. Previously, corticosteroids were used to treat chronic hepatitis B, but in the 1980s, many studies concluded that such treatment produced no beneficial effects and that they caused HBV reactivation [9].
Kim et al. [10] reported the risk of HBV reactivation in HBsAg-positive patients with asthma or chronic obstructive pulmonary disease, who were treated with systemic corticosteroids, especially when systemic corticosteroids were administered chronically or at high doses. For renal disease, since immunosuppression can facilitate viral replication and lead to the exacerbation of hepatitis B, Tse et al. [11] indicated the importance of the serial monitoring of HBV DNA and transaminase levels, as well as prompt anti-viral therapy, in the management of HBsAg-positive lupus patients. However, in resolved cases, as in our case, HBV reactivation and DNH infrequently occur. The risk factors for HBV reactivation are known to include detectable HBsAg, HBV DNA, HBeAg, HBcAb, HBV genotype, younger age, and male sex [12]. In our case, we could not determine the HBV genotype, because HBV-DNA disappeared immediately after taking entecavir. The reactivation of HBV might be related to the degree of renal failure, and the using and tapering of corticosteroids.

Recently, some chimeric monoclonal antibodies were used for several diseases, and this single-use or combination chemotherapy with other drugs has been identified as a risk factor for $\mathrm{HBV}$ reactivation in $\mathrm{HBsAg}$-negative patients, such as malignant lymphoma and rheumatic disease $[2,3]$. More recently, chimeric monoclonal antibodies, such as rituximab and eculizumab, are beginning to be used in some renal diseases [13-15]. Mansfield et al. [13] have documented the long-term efficacy and safety of a rituximab-based cyclophosphamide-sparing regimen for renal ANCA-associated vasculitis [13]. As shown in the current case report, DNH might occur even in patients given corticosteroids alone. Furthermore, currently, chimeric monoclonal antibodies are used in renal diseases more than 
ever and, therefore, there may be an increase in patients with DHN. For the management of HBV-infected patients and the prevention of HBV reactivation caused by immunosuppressive or cytotoxic therapy, some guidelines and proposed algorithms have been published [3, 16, 17]. Prior to the initiation of such immunosuppressive or cytotoxic therapy, these guidelines and algorithms recommend that screening be conducted in all cases for $\mathrm{HBV}$-associated serological markers (HBsAg, HBcAb, and HBsAb) [16, 17]. Even in renal disease, to prevent the development of HBV reactivation caused by immunosuppressive or cytotoxic therapy, diagnosis regarding chronic HBV infection, as well as resolved HBV infection, needs to be carried out. Importance should be placed on the confirmation of levels of HBV propagation, even in resolved cases, by measurement of HBV DNA levels [16, 17]. Careful screening and monitoring of HBV appear to be the most rational approach for managing patients of renal disease, including MPOANCA-related nephritis, with previous HBV infection in patients who require immunosuppressive or cytotoxic therapy, including corticosteroids alone.

When HBV reactivation is diagnosed, it is mandatory to suspend all chemotherapy and start treatment with antiviral agents immediately. Currently, five oral nucleotide antiviral drugs are approved for the treatment of chronic HBV infection: lamivudine, adefovir, entecavir, tenofovir, and telbivudine [18]. The most commonly used antiviral drug in HBV reactivation is lamivudine [1]. However, Tse et al. [11] reported five patients who had received lamivudine for hepatitis B in lupus nephritis, and 1 of 5 patients developed of lamivudine resistance. In our patient, entecavir was remarkably effective, providing rapid normalization of $\mathrm{HBV}$ reactivation. Antiviral treatment with entecavir was immediately initiated when the patient had HBV reactivation, and a rapid reduction of viral replication with normalization of transaminases was obtained. Entecavir, a new nucleoside analogue, is reported to induce few drug-resistant mutant viruses, unlike lamivudine, and, therefore, has replaced lamivudine $[3,16]$. However, there is little evidence that entecavir is more favorable than lamivudine in the treatment of DNH [10]. Generally, entecavir is preferred because of its rapid onset of action and lack of nephrotoxicity. In addition, several reports have shown that the administration of entecavir is effective in the prevention of HBV reactivation [3, 16].

In conclusion, we describe a case of DNH in MPOANCA-related MPA treated with corticosteroids. HBV infection, especially resolved infection, is overlooked in renal diseases. To prevent $\mathrm{HBV}$ reactivation and $\mathrm{DNH}$ induced by immunosuppressive or cytotoxic therapy, including corticosteroids alone, the measurement of HBVrelated serological markers needs to be performed prior to the initiation of such therapy, even in renal diseases.
Conflict of interest None declared.

\section{References}

1. Lok ASF, McMahon BJ. Chronic hepatitis B: update 2009. Hepatology. 2009;50:661-2.

2. Manzano-Alonso ML, Castellano-Tortajada G. Reactivation of hepatitis B virus infection after cytotoxic chemotherapy or immunosuppressive therapy. World J Gastroenterol. 2011;17: 1531-7.

3. Mastroianni CM, Lichtner M, Citton R, Del Borgo C, Rago A, Martini H, Cimino G, Vullo V. Current trends in management of hepatitis B virus reactivation in the biologic therapy era. World $\mathrm{J}$ Gastroenterol. 2011;17:3881-7.

4. Noterdaeme T, Longrée L, Bataille C, Deroover A, Lamproye A, Delwaide J, Beguin Y, Honoré P, Detry O. Liver transplantation for acute hepatic failure due to chemotherapy-induced HBV reactivation in lymphoma patients. World J Gastroenterol. 2011; 17:3069-72.

5. Jennette JC, Thomas DB. Pauci-immune and antineutrophil cytoplasmic autoantibody-mediated crescentic glomerulonephritis and vasculitis. In: Jennette JC, Olson JL, Schwartz MM, Silva FG, editors. Pathology of the kidney. Philadelphia: Lippincott Williams \& Wilkins; 2007. p. 643-73.

6. Nachman PH, Jennette JC, Falk RJ. Primary glomerular disease. In: Taal MW, Chertow GM, Marsden PA, Skorecki K, Yu ASL, Brenner BM, editors. Brenner \& Rector's the kidney. Philadelphia: Elsevier Saunders; 2012. p. 1100-91.

7. Sakai H, Kurokawa K, Koyama A, Arimura Y, Kida H, Shigematu S, Suzuki S, Nihei H, Makino H, Ueda N, Kawamura T, Gejyo F, Saito T, Harada T, Hiki Y, Yoshida M. Clinical guideline for rapidly progressive glomerulonephritis in Japan. Jpn J Nephrol. 2002;44:55-82.

8. Yamagata K, Usui J, Saito C, Yamaguchi N, Hirayama K, Mase K, Kobayashi M, Koyama A, Sugiyama H, Nitta K, Wada T, Muso E, Arimura Y, Makino H, Matsuo S. ANCA-associated systemic vasculitis in Japan: clinical features and prognostic changes. Clin Exp Nephrol. 2012;16:580-8. doi:10.1007/s10157012-0598-2.

9. Hoofnagle JH, Davis GL, Pappas SC, Hanson RG, Peters M, Avigan MI, Waggoner JG, Jones EA, Seeff LB. A short course of prednisolone in chronic type B hepatitis. Report of a randomized, double-blind, placebo-controlled trial. Ann Intern Med. 1986; 104:12-7.

10. Kim TW, Kim MN, Kwon JW, Kim KM, Kim SH, Kim W, Park HW, Chang YS, Cho SH, Min KU, Kim YY. Risk of hepatitis B virus reactivation in patients with asthma or chronic obstructive pulmonary disease treated with corticosteroids. Respirology. 2010;15:1092-7.

11. Tse KC, Yung S, Tang C, Yip TPC, Chan TM. Management of hepatitis $\mathrm{B}$ reactivation in patients with lupus nephritis. Rheumatol Int. 2009;29:1273-7.

12. Lubel JS, Testro AG, Angus PW. Hepatitis B virus reactivation following immunosuppressive therapy: guidelines for prevention and management. Intern Med J. 2007;37:705-12.

13. Mansfield N, Hamour S, Habib AM, Tarzi R, Levy J, Griffith M, Cairns T, Cook HT, Pusey CD, Salama AD. Prolonged diseasefree remission following rituximab and low-dose cyclophosphamide therapy for renal ANCA-associated vasculitis. Nephrol Dial Transplant. 2011;26:3280-6.

14. Fervenza FC, Cosio FG, Erickson SB, Specks U, Herzenberg AM, Dillon JJ, Leung N, Cohen IM, Wochos DN, Bergstralh E, Hladunewich M, Cattran DC. Rituximab treatment of idiopathic membranous nephropathy. Kidney Int. 2008;73:117-25. 
15. Garjau M, Azancot M, Pamos R, Sánchez-Corral P, Montero MA, Serón D. Early treatment with eculizumab in atypical haemolytic uraemic syndrome. Clin Kidney J. 2012;5:31-3.

16. Ohishi W, Chayama K. Prevention of hepatitis B virus reactivation in immunosuppressive therapy or chemotherapy. Clin Exp Nephrol. 2011;15:634-40.

17. Kusumoto S, Tanaka Y, Mizokami M, Ueda R. Reactivation of hepatitis B virus following systemic chemotherapy for malignant lymphoma. Int J Hematol. 2009;90:13-23.
18. Shamliyan TA, MacDonald R, Shaukat A, Taylor BC, Yuan JM, Johnson JR, Tacklind J, Rutks I, Kane RL, Wilt TJ. Antiviral therapy for adults with chronic hepatitis B: a systematic review for a National Institutes of Health Consensus Development Conference. Ann Intern Med. 2009;150:111-24. 